\title{
Biochemical Changes and Risk Factors in the Prognosis of Antibiotics Susceptibility in Urinary Tract Infections
}

\author{
ANDREI VATA ${ }^{1,2 \#}$, IOANA MARIA HUNEA ${ }^{1,2 * \#}$, OLIVIA DORNEANU ${ }^{1,2 \#}$, IOANA ALINA HARJA-ALEXA ${ }^{1 \#}$, CLAUDIA PLESCA $^{1}$, \\ GEORGIANA LEONTE-ENACHE ${ }^{1}$, ALEXANDRA CIOCAN ${ }^{1}$, CRISTINA MIHELA GHICIUC ${ }^{1}$, IRINA ESANU ${ }^{1}$, MIHAI MANOLACHE ${ }^{3}$, \\ CATALINA MIHAELA LUCA ${ }^{1,2 \#}$ \\ IUniversity of Medicine and Pharmacy Grigore T.Popa, 16 Universitatii Str., 700115, Iasi, Romania \\ ${ }^{2}$ Hospital of Infectious Diseases Sfanta Parascheva, 2 Octav Botez Str.,700116, Iasi, Romania \\ ${ }^{3}$ CEBIS International SAGL, Via Magio 1C, 6900, Lugano, Switzerland
}

\begin{abstract}
The aim of our study was evaluation of prevalence of uncomplicated and complicated urinary tract infections (UTIs) among patients with UTIs associated with Gram - negative bacteria and analysis of prognostic risk factors in complicated UTIS. Weretrospectivelyanalyzed the medical records of inpatients with diagnosis of UTI based on clinical, biological and microbiological assay. Susceptibility tests for different antimicrobial categories were performed. Risk factors in complicated UTIs were correlated with pathogens' susceptibility. A total of 96 eligible patients were analyzed. Complicated UTIs were identified in $66.67 \%$ cases. The most frequent uropathogens isolated were E.coli and Klebsiella species. Exrtrarenal factors and nephropathic disease were the most common factors associatedwith an increased prevalence of multi -drug resistant isolates. Knowledge of the spectrum of the possible pathogens and local resistance patterns are very important for the antibacterial treatment outcome.
\end{abstract}

Keywords: complicated urinary tract infections, risk factors, multi - drug resistance

Urinary tract infections are one of the most common infections in both inpatients and outpatients.

Because of the anatomical particularities, women are more frequent affected. Up to $60 \%$ women have UTIS during their lifetime and 10\% female have at least one episode of UTI yearly[1].

Diagnosis of UTIs is based on the combinations of symptoms and positive urine analysis and culture. Clinically, UTIs are differentiated into lower (cystitis) and upper (pyelonephritis) infections [2,3]. Microbiological identification of significant bacteriuria is at least $\geq 10^{6} \mathrm{CFU} /$ $L$ for men and $\geq 10^{5} \mathrm{CFU} / \mathrm{L}$ for women[4]. Based on the severity of disease, urinary tract infections are classified into uncomplicated and complicated infections. While uncomplicated infections are frequent in otherwise healthy non - pregnant women, complicated urinary infections have specific hosts (with increased risks to develop complications). Male gender, pregnant women, immunosuppression (e.g. diabetes), anatomical or functional abnormalities of the urinary tract (e.g. renal stones, indwelling catheters or other drainage devices, renal failure, renal transplant, neurogenic bladder, etc) are predisposing factors for complicated UTIs [5]. One of the most important differences betw een the two categories is the therapeutic approach due to an increased risk of recurrence, complications or treatment failure due to antimicrobial resistance in complicated UTIs [6]. Most of the UTIs are monobacterial; Escherichia coli is the most common pathogen involved. Other pathogens responsible for uncomplicated UTIs are Klebsiella pneumoniae, Staphylococcus saprophyticus, Enterococcus faecalis, group B streptococci, Proteus mirabilis [1]. On the other side, complicated UTIs are frequently associated with antibiotic - resistant microorganisms, like methicillinresistant staphylococci, vancomycin-resistant enterococci (VRE) and Gram-negative bacteria, mainly those producing AmpC enzymes or extended-spectrum $\beta$-lactamases (ESBLs) [4].
Of particular concern are members of the family Enterobacteriaceae, including E. coli and Klebsiella pneumoniae. According to lastEuropean Centre for Disease Prevention and Control (ECDC) report, Romania records a significantly higher antimicrobial resistance compared to European average, mainly for Klebsiella pneumoniae and Enterococcus, while $E$. coli is dealing with an increase resistance in Europe [7].

The increase of bacterial resistance to antibiotics or multi drug resistance (MDR) resulted in significantly limited treatment options. In addition, previous antibiotics administration could be considered an important predictor for antimicrobial resistance [8].

In this context, the aim of the present paper was to evaluate the epidemiological, etiology andsusceptibility patterns of uncomplicated and complicatedUTIs based on clinical practice in the lasi Clinic of Infectious Diseases during 12-month interval.

The study was approved by the Ethics Committee of the Clinic of Infectious Diseases, lasi.

\section{Experimental part}

Studied patients This was a retrospective analysis of hospital-based medical records of patients with diagnosis of UTI hospitalized in laOi Clinic of Infectious Diseases during a 12 months period between 2017 and 2018. In the study were included in-patients with microbiological confirmed UTI produced by Gram negative bacteria (defined by growth of $\geq 10^{5} \mathrm{UFC} / \mathrm{L}$ ). Exclusion criteria: outpatients; UTIs produced by Gram-positive bacteria; polymicrobial bacteriuria.

Data collection: demographic data, medical and medication history, clinical data, blood and urine tests, susceptibility tests, treatment administered and outcome.Risk factors for complicated UTIs were recorded.All blood, urine culture and susceptibility tests urine tests were performed by the central hospital's 
laboratory. Susceptibility tests were performed using a disk diffusion assay on agar Mueller-Hinton. Susceptibility tests included betalactamines (ampicillin,piperacillin/ tazobactam), nitrofurantoin, third generation cephalosporins, carbapenems, fluoroquinolones (ciprofloxacin). Identification of bacterial species was performed using biochemical tests, either manually or using miniAPI system (BioMerieux, France). The results were interpreted according to the European Committee on Antimicrobial Susceptibility Testing (EUCAST) guidelines. Multi drug resistance (MDR) was defined as non-susceptibility to at least one agent in three or more antimicrobial categories [9].

\section{Statistical analysis}

Patients with complete dataset were included in statistical analysis. Data were analyzed by descriptive statistics. The correlation between risk factors and antimicrobial susceptibility was performed using Pearson test in XLSTAT version 2019 software.

\section{Results and discussions}

\section{Patient characteristics}

We identified 105 cases of UTIs hospitalized between 2017-2018 in our hospital. Of these, Gram - negative pathogens were identified in 93 cases of UTIs. All cases were included in statistical analysis. Most of the patients were female $(71.87 \%$ cases). The mean age ( \pm St. dev.) was $53 \pm 21.45$ years, but the majority of patients were over 50 years old. Uncomplicated UTIs were noted in only $33.33 \%$ case, mainly women (fig. 1 ).

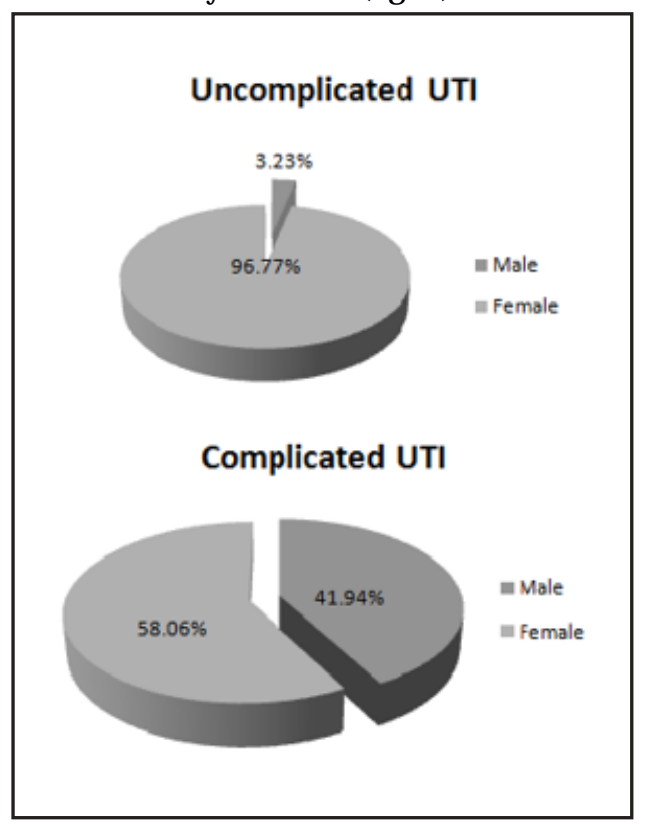

Fig. 1. Gender repartition in uncomplicated and complicated UTIS

Clinicaldata and risk factors In patients with uncomplicated UTIs prevailed lower urinary infections (cystitis) in contrast to complicated UTIs. In patients with risk factors, symptoms of pyelonephritis were identified in $83.87 \%$ cases (fig. 2).

The risk factors for complicated UTIs were gender and recurrenttract infections, followed by extrarenal (diabetes) and renal (hydronephrosis) (fig. 3).

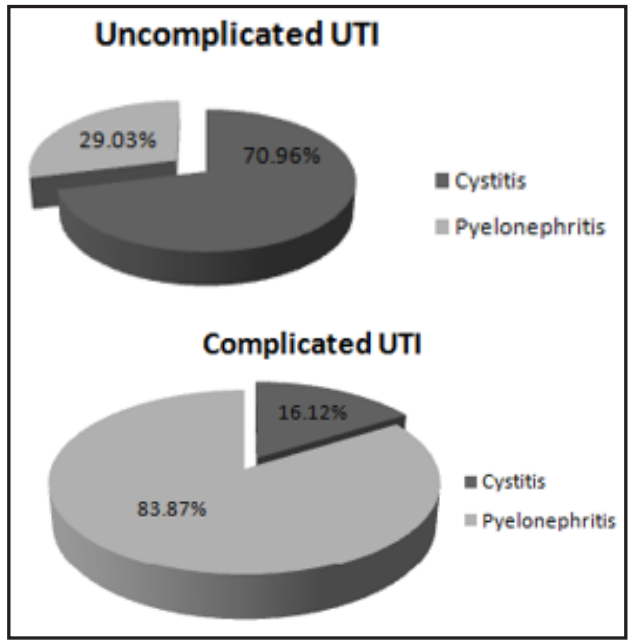

Fig. 2. Clinical manifestations in uncomplicated and complicated UTIS

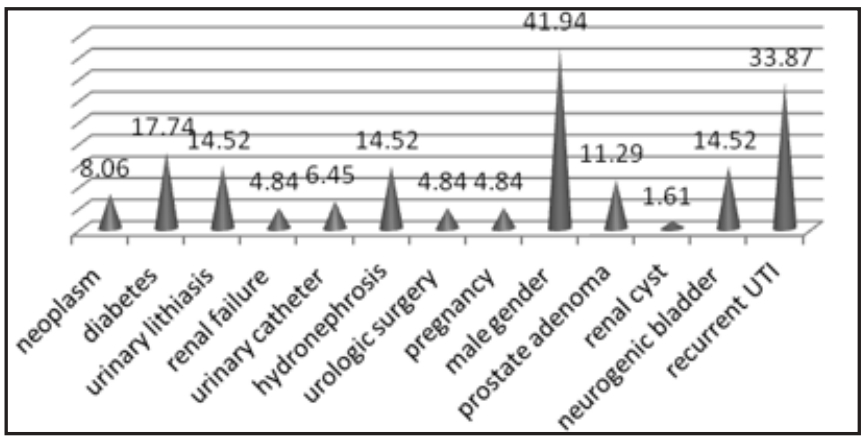

Fig. 3. Risk factors in complicated UTIS

\section{Microbiological data}

The most frequent pathogen identified in both uncomplicated and complicated UTIs were Escherichia coli(75.8\% isolates) andKlebsiellaspp.( $8.06 \%$ isolates). Other Enterobacteriaceae (Proteus, Serratia, Pseudomonas) were found only in isolates of complicated UTI (fig. 4).

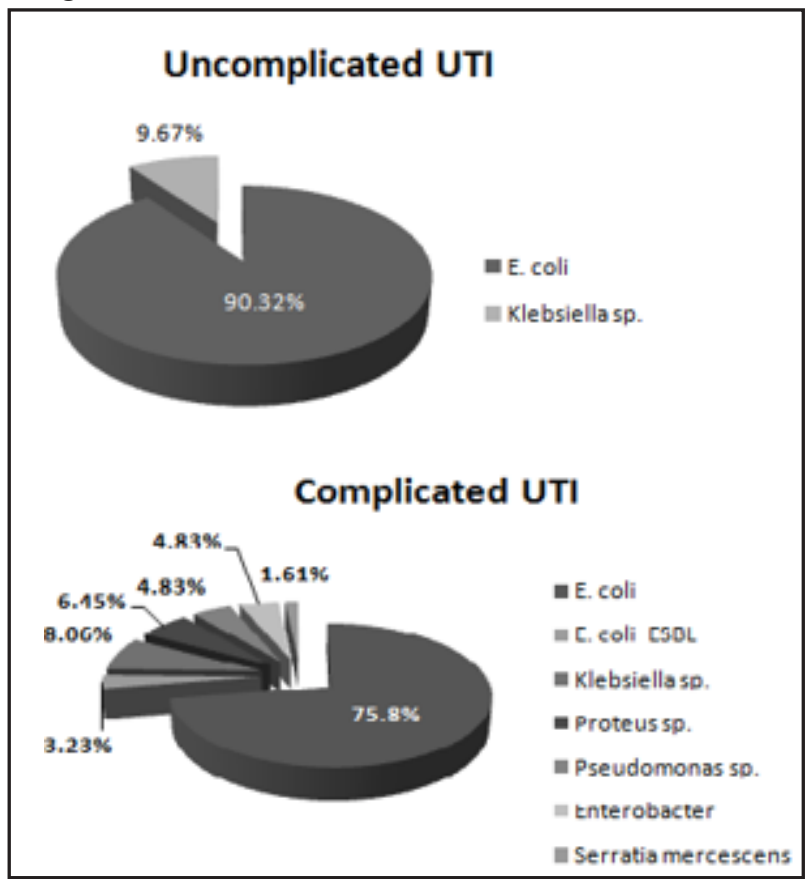

Fig. 4. Pathogens involved in uncomplicated and complicated UTIS 


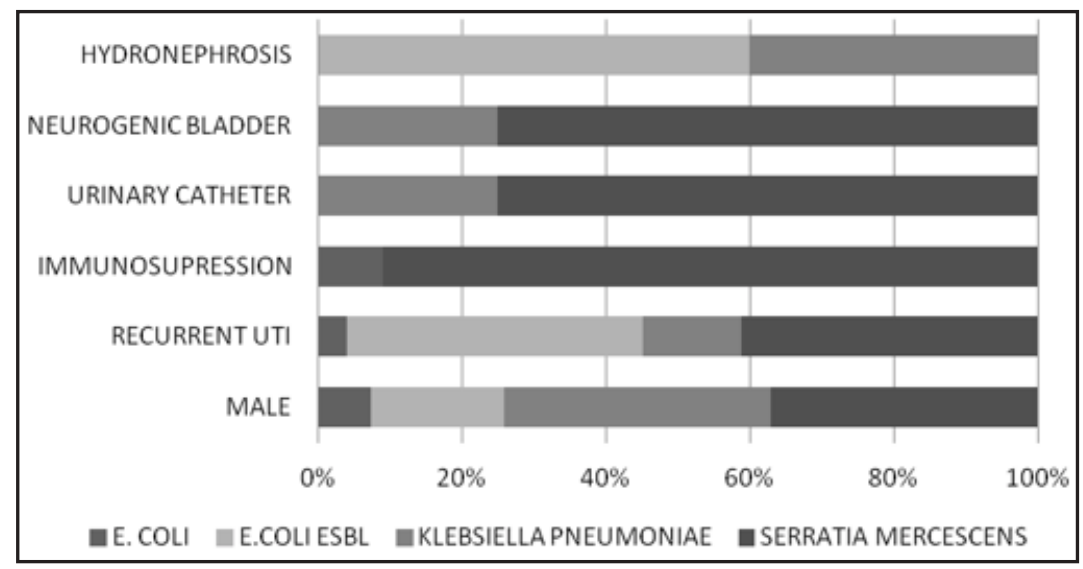

Fig. 5. Risk factors associated with MDR in complicated UTIs

\section{Susceptibility results}

Only one isolate of E. coli and one of Klebsiella pneumoniae were identified in uncomplicated UTI. Pathogens MDR were recorded in isolates of Klebsiella pneumoniae $(60 \%)$, Proteus group $(25 \%)$ and E. coli $(10.6 \%)$. All cases of $E$. coli ESBL were MDR. The most frequent risk factors associated with $E$. coli MDR infections were recurrent UTIs ( $40 \%$ cases), while gender and diabetes counted $20 \%$ cases. Almost similar factors were involved in $E$. coli $\mathrm{ESBL}$ infections. However, only a moderate correlation between antimicrobial resistance and diabetes (Pearson coefficient $=0.44$ ) and history of UTI (Pearson coefficient $=0.4$ ) was obtained, but this result could be biased by the small sample size of our study.

All isolates of Klebsiella MDR were recorded in male with other renal risk factors (urinary catheterization, hydronephrosis, recurrentUTI) and represented 33\% cases (fig. 5).

\section{Treatment and outcome}

The median duration of hospitalization was 8 days. In both uncomplicated and complicated UTIs, patients received antibiotic treatment based on $3^{\text {rd }}$ generation of cephalosporins (38.54\% cases) and /orfluoroquinolones (21\% cases). Carbapenemes were administered in complicated UTIs ( $10 \%$ cases). Most of the patients were recovered and only $8.3 \%$ cases of renal failure and one case of death were recorded.

In this single center retrospective study, we evaluated the antimicrobial resistance of uropathogens responsible for UTIs in patients with and without risk factors. The diagnosis of uncomplicated and complicated UTI was based on combination of clinical manifestations, biological and urine culturesandcomorbidities. Empiric treatment was adaptedbased on susceptibilitytestsand included the most common antibiotics used in current clinical practice for the management of UTIs. In our small cohort prevailed complicated UTIs (66.6\% cases) similarly with data reported in other east European countries. Stefaniuk et al (2016) noted a prevalence of $37.8 \%$ for uncomplicated UTIs in 396 patients[10].

The most common uropathogen identified in UTIs was Escherichiacoli, followed byKlebsiella spp., as also reported Stefaniuk etal. (2016) who have found in their study a high prevalence of E. coliin UTIs (71.4\%)[10]. Similar results were found previously in our hospital by Luca et al. (2013) in pregnant women ( $E$. coli in $88.3 \%$ cases and Klebsiella spp. in $6.7 \%$ cases) [11]. Likewise, this etiology was also predominant during 2018in our clinic [12]. Of these, $60 \%$ isolates of Klebsiella spp.and $10.6 \%$ isolates of E.coli were MDR. We have not identified sufficient cases of Pseudomonasin order to analyze its susceptibility profile.
These results were somehow expected and they were in accordance with the ECDC surveillance report (2017) that found an increased resistance of $E$. coliamong European countries, mainly for aminopenicillins (58.7\%). Klebsiella spp. resistance was over $30 \%$ in our study. However, Romania recorded a decrease of antimicrobial resistance of $E$. coli, but maintained an increased resistance for Klebsiella pneumoniae compared to European average[ 7].Risk factors associated with this etiology were renal (hydronephrosis, indwelling urinary catheterization and recurrent urinaryinfections) and extrarenal (diabetes). History of UTIs and diabetes were significantly associated with uropathogens, mainly E. coli[13].

In our study, increased prevalence of $E$. coli infections was reported in pyelonephritis developed on obstructive uropathy. We have found that urinary catheterization was frequently associated with Klebsiella infections. This strongcorrelation was also found by our colleagues from the Urological Clinic, Parhon Hospital (lasi) who reported a prevalence of $46.15 \%$ cases of UTIs produced by Klebsiella MDR in patients with urethro-vesical catheter $[14,15,16,17]$. The European multicenter observational (RESCUING) study that included also our hospital, investigated management of complicated UTIs in countries with high prevalence of MDR. In 1006 isolates, urinary catheterisation was the most underlying condition associated with Gram - negative UTIs, mainly Klebsiella pneumoniae MDR (identified in 53\% cases) [18]. The distribution of uropathogens and their susceptibility patterns may vary among countries, regions or even within hospitals[19-21]. However, our results showed that our hospital our hospital fits into the antimicrobial resistance profile for our county, as previously described in other studies $[14,18]$.

\section{Conclusions}

Our retrospective analysis revealed that an important proportion of symptomatic patients admitted to the hospital had complicated UTI. An increased MDR rate has been observed among Klebsiella spp. and E. coli isolates. The associated risk factors were correlated with antimicrobial susceptibility and had an essential role in antibacterial treatment outcome.

\section{References}

1.SOBEL J D, KAYE D. Urinary tract infections. In: Mandell GL, Bennett $J E$, eds. Principles and Practice of Infectious Diseases, 8th ed. Philadelphia: Elsevier Saunders, 2014, p. 886.

2.FLORES-MIRELES AL, WALKER J N, CAPARON M, HULTGREN SJ . Nat Rev Microbiol., 13, no. 5, p. 269, 2015.

3.MAZZULLI T. Can J Urol.,19, no. 1, 2012, p. 42. 
4.PALLETT A, HAND K. J Antimicrob Chemother., 65, no. 3, 2010, p. 25. 5.BONKAT G, PICKARD R, BARTOLETTI R, BRUYERE F, GEERLINGS SE, WAGENLEHNER F. ARNHEM, https://uroweb.org/wp-content/ uploads/19-Urological-infections_2017_web.pdf

6.GEERLINGS, S.E., Microbiol Spectr;4, no. 5, 2016, p.1.

7.***European Center for Disease Prevention and Control. https:// ecdc.europa.eu/sites/portal/files/documents/AMR-surveillance-EARSNet-2017.pdf

8.VAN DER STARRE WE, VAN NIEUWKOOP C, PALTANSING S, VAN'T WOUTJW, GROENEVELD GH, BECKER MJ , KOSTER T, WATTEL-LOUIS GH, DELFOS NM, ABLIJ HC, LEYTEN EM, BLOM JW, VAN DISSEL JT. J Antimicrob Chemother.66, no. 3, 2011, p. 650.

9.MAGIORAKOS AP, SRINIVASAN A, CAREY RB, CARMELI Y, FALAGAS ME, GISKE CG, HARBARTH S, HINDLER JF, KAHLMETER G, OLSSONLILJ EQUIST B, PATERSON DL, RICE LB, STELLING J , STRUELENS MJ, VATOPOULOS A, WEBER JT, MONNET DL. Clin Microbiol Infect., 18, no. 3, 2012, p. 268.

10.STEFANIUK E, SUCHOCKA U, BOSACKA K, HRYNIEWICZ W. EUr J Clin Microbiol Infect Dis.,35, no. 8, 2016, p.1363.

11.LUCA, M.C., VATA, A., DORNEANU, O., JUGANARIU, G., DOROBAT, C. ,BMC Infect Dis. 13, no. 1: 09, 2013

12.MIHAI IF, LACATUSU AG, FILIP-CIUBOTARU F, DOROBAT C, ROMANESCU C, MANCIUC C. Global Advanced Research Journal of Microbiology,8, no. 2, 2019, p. 35.

13.WOLDEMARIAM HK, GELETA DA, TULU KD, ABER NA, LEGESE MH, FENTA GM, ALI I. BMC Infect Dis., 19, no. 1, 2019, p.43.
14.PRICOP, C., SUDITU, N., VRINCEANU, R., PUIA, D., DIMITRIU, D.C., CIUTA, C., TODOSI, L., CHECHERITA, I.A.,. Nobel Med, 11, no. 3, 2015, p.42.

15.MACOVEI, L.A., CRISTESCU, V., DEBITA, M., et al. Rev.Chim.( Bucharest), 68, no. 10, 2017, p. 2440-2442.

16.LECA, D., CALIN, A.,M., EARAR, K., NECHITA, A., CHISCOP, I., DOROBAT, G., DOROBAT, C., ILIE, M., DEBITA, M. Rev.Chim. (Bucharest), 66, no.12, 2015, p.2005-2008

17.GAVRILOVICI, C, LUCA, A, ANTONIU, SA, GALLABY, K, STEFANESCU, R, STARCEA, M, MIRON, I, BILD, V. Farmacia, 66, 2018, no. 2, p. 197208.

18.GOMILA A, CARRATALA J , ELIAKIM-RAZ N, SHAW E, WIEGAND I, VALLEJ O-TORRES L, GOROSTIZA A, VIGO JM, MORRIS S, STODDART $M$, GRIER S, VANK C, CUPERUS N, VAN DEN HEUVEL L, VUONG C, MACGOWAN A, LEIBOVICI L, ADDY I, PUJ OL M; COMBACTE MAGNET WP5 RESCUING STUDY GROUP AND STUDY SITES. Infect Drug Resist.,18, no. 11, 2018 p. 2571.

19.FARRELL DJ , MORRISSEY I, DE RUBEISD, ROBBINSM, FELMINGHAM D. J Infect.,46, no. 2, 2003 p. 94.

20.SOMASHEKARA SC, DEEPALAXMI S, JAGANNATH N, RAMESH B, LAVEESH MR, GOVINDADAS D. J Basic Clin Pharm., 5, no. 4, 2014, p.105.

21.CUSINI A, HERREN D, BUTIKOFER L, PLÜSS-SUARD C, KRONENBERG A, MARSCHALL J. Antimicrob Resist Infect Control., 7, 2018, p. 89.

Manuscript received: 5.10 .2018 